\title{
Avanços e dificuldades para o mercado de trabalho
}

FERNANDO AUGUSTO MANSOR DE MATTOS ${ }^{I}$

\section{Apresentação}

$\mathrm{N}$

OS ANOS iniciais do século XXI, o mercado de trabalho brasileiro passou por importantes avanços. A formalização do mercado de trabalho reverteu duas décadas de redução da proporção de trabalhadores que se inseriam no espaço ocupacional sem acesso a Direitos Trabalhistas, Sociais e Previdenciários. Da mesma forma, no período 2000-2014, com mais ênfase a partir de 2004, houve crescimento da renda real do trabalho, conjugada com redução das desigualdades pessoais de rendimentos.

O objetivo deste artigo é discutir essas mudanças e suas causas, além de apontar para as dificuldades que se colocam, no curto e no médio prazos, para a manutenção das melhorias já obtidas e para uma eventual (e desejada) estruturação do mercado de trabalho. Entre as dificuldades de curto prazo destacam-se os efeitos da política econômica adotada pelo segundo governo Dilma e, para o médio prazo, o desafio de enfrentar sintomas do processo de desindustrialização em curso e seus impactos em termos de qualidade dos postos de trabalho a serem criados no futuro. Nas conclusões são apontados alguns fatores políticos que obstaculizam a definição de um novo padrão de crescimento.

\section{Desempenho da economia}

\section{e efeitos sobre os indicadores do mercado de trabalho}

A recuperação da economia e a melhoria do mercado de trabalho ocorridos no período 2004-2008 contrastam com o que ocorrera entre 1998 e 2003, quando a economia operou com baixo crescimento e alta inflação. Entre 2004 e 2008, houve inflação declinante do crescimento do PIB, explicado tanto pela demanda externa exercida pelo aquecimento da economia internacional e, em especial, pela China, como também por medidas tomadas pelo governo federal que afetariam a atividade econômica e, por consequência, o mercado de trabalho, nos anos seguintes. Em 2009, a economia sofreu os impactos da crise internacional, mas recuperou-se logo em seguida, crescendo 7,5\% em 2010, de tal forma que no biênio 2009-2010, a economia manteve, na média, crescimento pouco abaixo do auge representado pelos cinco anos do intervalo 2004-2008. A partir de 2011, porém, a economia adentra um período de desaceleração, que somente não teve impacto maior no mercado de trabalho porque as medidas tomadas de incentivo ao consumo ainda promoveram crescimento não desprezível no volume de ocupações criadas, especialmente nas atividades de construção 
civil, de comércio e reparação e de algumas atividades de serviços privados, além de empregos na administração pública. Desde 2010, como reflexo tanto da crise internacional como da desaceleração dos investimentos, a produção e o emprego industriais desaceleraram significativamente, sendo os principais responsáveis pelo fraco desempenho do PIB desde então. Tal cenário aponta para uma perspectiva preocupante para o futuro desempenho da economia e, por conseguinte, do mercado de trabalho, conforme se pretende comentar a seguir.

Em 2003, o governo Lula recém-empossado dedicou-se especialmente a conter as pressões inflacionárias que vinham sendo transmitidas desde meados de 2002 pela desvalorização cambial ocorrida naquele ano. O aumento da taxa Selic e da meta de superávit primário procurou exercer essa tarefa, mas o controle da inflação na verdade foi viabilizado pela apreciação cambial advinda da melhora (que se acentuaria nos anos seguintes) das relações de troca e da expansão da demanda externa, gerando aumento nos preços das commodities exportadas pelo Brasil. A economia somente começaria a crescer de forma sustentada a partir de 2004, inicialmente puxada pela demanda externa ${ }^{1}$ (Baltar, 2015), mas logo a seguir também impulsionada por medidas voltadas para a recuperação do crédito, ${ }^{2}$ que ampliou o consumo das famílias, e pela retomada dos investimentos produtivos, também beneficiados pelo barateamento de bens de capital importados, devido à valorização cambial.

Os sinais de retomada da atividade econômica já estavam claros em meados de 2004, ano que se encerraria com a criação de 1.523 milhão de empregos formais, segundo dados do Cadastro Geral de Empregados e Desempregados, um recorde até então (Gráfico 1 ). ${ }^{3}$ Esse cenário de retomada da atividade econômica e de ampliação do consumo, induzido tanto pela melhora do próprio mercado de trabalho quanto pelas políticas de transferência de renda, gerou expectativas positivas para os investimentos privados, esses sim (Barbosa, 2012) os principais motores do crescimento que veio a seguir. Entre 2005 e 2008, a taxa de investimento em relação ao PIB cresceu continuamente, passando de $15,9 \%$, em 2005, para 19,1\%, em 2008, somente retrocedendo em 2009, por efeito do rebatimento da crise do subprime.

O ano 2006 inicia-se com política expansionista tanto pelo lado fiscal quanto pelo lado monetário, notabilizando-se uma nova postura da política econômica, especialmente a partir da troca de comando ocorrida em março no Ministério da Fazenda. O ano também é marcado por um aumento (ao qual resolutamente se opuseram economistas ortodoxos/conservadores de grande presença na mídia "especializada" em economia) recorde do valor do salário mínimo (14\%) e na definição da regra de ajuste que vigoraria nos anos seguintes. O mercado de trabalho mantinha uma trajetória de expansão, com a geração de 1.254 milhão de empregos formais em 2005 e mais 1.229 milhão em 2006, culminando com um novo recorde, de pouco mais de 1.600 milhão postos formais de trabalho, em 2007, quando é lançado o PAC, que contemplava investimentos públicos 
em diversas obras de infraestrutura e também uma ampliação dos investimentos da Petrobras. Nesse mesmo ano, amplia-se o Programa Bolsa Família, tanto no número de famílias contempladas como também nos valores reais dos benefícios.

O crescimento do valor real do salário mínimo teve efeito importante não apenas nos rendimentos auferidos no mercado de trabalho, mas também no valor real dos benefícios sociais, pois eles são atrelados ao salário mínimo. ${ }^{4}$ Dessa forma, amplia-se a massa de rendimentos das famílias, em contexto de queda de desemprego, o que favorece novas rodadas de expansão do consumo e do crédito, ainda mais no contexto de inflação baixa permitida pela valorização cambial viabilizada pelo cenário externo. Os aumentos reais de salários (o salário real médio começa a subir significativamente a partir de 2004, e teria um aumento real acumulado de cerca de $35 \%$ entre 2004 e 2013 , segundo dados oficiais do IBGE) se consolidam em um ambiente de aumento do poder de barganha dos trabalhadores dos setores mais organizados. ${ }^{5}$ No caso dos trabalhadores dos segmentos informais do mercado de trabalho, o salário mínimo em ascensão tem um efeito notável, por influenciar na formação de preços dos vendedores de bens e de serviços, ${ }^{6}$ ainda mais em contexto de aquecimento da atividade economia.

Em 2008, porém, diante de temores de retomada da inflação, o BC volta a subir a Selic, a partir de abril, poucos dias antes da quebra do Banco Lehman Brothers, que deflagraria a crise internacional. De todo modo, o PIB cresce não desprezíveis $5,0 \%$ e o mercado de trabalho ainda gera 1.540 milhão de postos formais de trabalho, quantidade menor do que a de 2007, mas superior às de 2006 e de 2005.

O governo reage à crise com políticas anticíclicas. O cenário só não foi pior porque o país havia acumulado reservas internacionais suficientes para suportar a reversão do cenário internacional, pelo menos por algum tempo. Entre as medidas anticíclicas destacam-se decisões de ampliação do Programa Bolsa Família, além de uma ampliação de investimentos públicos. Decidiu-se também pelo aumento da liquidez, mediante a redução do compulsório dos bancos, o que viabilizou a ampliação do crédito interno. Do ponto de vista da política fiscal, as autoridades econômicas optaram por manter as despesas primárias em 2009 e 2010, apesar da queda (inicial) da arrecadação. O "ajuste" se deu pela redução do superávit primário, que caiu para uma média de $1,3 \%$ do PIB no biênio 2009-2010, contra 2,4\% no triênio 2006-2008. ${ }^{7}$ Houve aumento das despesas correntes, e manutenção da regra de aumento real do salário mínimo, ${ }^{8} \mathrm{o}$ que permitiu a ascensão das despesas com a Previdência, com o abono salarial e com o seguro-desemprego - com impactos positivos sobre o consumo. Importante também foi a expansão da oferta de crédito por parte dos bancos públicos, como Banco do Brasil, Caixa Econômica Federal e, notadamente, o BNDES. Essas medidas não impediram a ocorrência de uma pequena retração do PIB em 2009 , mas pelo menos mantiveram um ritmo positivo de criação de postos formais de trabalho: no ano, apesar da retração de $0,2 \%$ do PIB, foram gerados 995 
mil postos formais de trabalho. Como resultado dessas medidas anticíclicas, em 2010 , o PIB atingiria a taxa de crescimento de $7,5 \%$, o que promoveu a geração líquida de 2.136 milhões de postos formais de trabalho no ano.

O cenário herdado pelo primeiro mandato de Dilma Rousseff, porém, não era alentador, a começar pelo fato de que, ao contrário de que aconteceu com Lula, o mandato de Dilma Rousseff iniciou-se com pouco espaço para valorizar o câmbio, fator que fora decisivo para que, durante os dois mandatos de Lula, tivesse sido possível conciliar inflação baixa ou declinante com crescimento econômico, apesar de ter mantido ainda alto superávit primário e juros muito elevados durante os seus oito anos. ${ }^{9}$ O primeiro mandato de Dilma ampliou os principais programas de transferências de renda herdados de Lula, e isso foi decisivo para manter certo dinamismo da geração de postos de trabalho, mas o fato de não ter podido se beneficiar do movimento cambial do qual fez uso o governo Lula, ${ }^{10}$ ademais de ter encontrado um cenário internacional mais desfavorável (nem tanto pela instabilidade financeira mundial, mas pelas consequências que a mesma vem produzindo sobre a divisão internacional do trabalho, ${ }^{11}$ desde a "digestão" da crise gerada em 2007/2008 e da estratégia que alguns países, especialmente a China, adotaram para enfrentá-la), colocou algumas dificuldades para manter o mesmo ritmo de crescimento anterior e, mais ainda, para a redefinição de um novo padrão de acumulação.

O primeiro mandato de Dilma iniciou-se mantendo (até agosto de 2011) a política de aumento de juros que vinha ocorrendo desde fevereiro de 2010. Sua equipe econômica - alegadamente para conter pressões inflacionárias e, principalmente, para abrir espaço para posterior redução dos juros - decidiu também adotar medidas chamadas de "macroprudenciais" que, na prática, abortaram o crescimento do crédito, o que prontamente promoveu uma forte desaceleração do consumo privado, especialmente de bens duráveis (Serrano; Summa, 2015, p.17). Além disso, decidiu-se pela ampliação (com efetivo cumprimento, no final do ano) de um superávit primário ainda maior do que fora praticado em 2010. Apesar de o cenário internacional não se revelar adverso em 2011 (não foram interrompidos os fluxos de capitais e a desaceleração das exportações foi pequena), o governo decidiu tomar essas medidas de restrição fiscal e de aumento de juros, que acabaram debilitando o consumo agregado e provocaram efeitos depressivos duradouros sobre os investimentos privados, ampliando o cenário de desaceleração que se materializara no final de 2010.

A partir de setembro de 2011, o Banco Central decidiu iniciar um ciclo de reduções das taxas de juros, que duraria até o início de 2013. Nesse período, ocorreu desvalorização cambial, como decorrência da própria redução dos juros. A aposta era de que essa nova combinação câmbio-juros promoveria uma retomada dos investimentos do setor privado, mas isso não correu, dado que os efeitos das políticas restritivas e dos controles "macroprudenciais" tomados no início do mandato haviam consolidado uma forte redução da demanda agregada, 
levando o setor privado a "ajustar" sua capacidade produtiva à nova realidade marcada pela desaceleração do consumo e do crédito. A constatação de que o investimento privado não reagia, ao mesmo tempo em que voltavam as preocupações com a inflação (em grande medida causada pela desvalorização cambial), levou a uma nova guinada na política monetária, e os juros voltariam a subir a partir de maio de 2013. Para "compensar" o setor privado, o governo ampliou medidas de isenções tributárias (incluindo desoneração de folha de pagamento para diversos setores de atividade), na vã tentativa de reanimar os investimentos produtivos. Nesse contexto, o cenário fiscal havia piorado muito, pois às desonerações somou-se a desaceleração da atividade, debilitando a arrecadação em todas as esferas da federação. A desaceleração já se materializara principalmente por meio da redução da taxa de investimento. Os dados falam por si: entre 2004 e 2010, o investimento global (público mais privado) cresceu a uma taxa média real de cerca de $8,0 \%$ ao ano (portanto, acima do crescimento do PIB), enquanto, no período 2011-2014, cresceu apenas a 1,8\% ao ano, conforme mostram Serrano e Summa (2015, p.23). A produção industrial permaneceu, ainda em 2013, nos mesmos níveis de 2008 (ou seja, pré-crise), conforme lembra Bastos (2015).

Nesse momento, acumulavam-se obstáculos para reestimular os investimentos públicos, em razão de fatores políticos, incluindo a inabilidade de negociação de marcos regulatórios com o setor privado - tudo isso sob um duro ambiente de oposição da grande imprensa contra o governo Dilma, em consonância com as críticas do sistema financeiro privado e de seus representantes, explícitos ou não, na mídia televisiva e na imprensa escrita, criando um clima adicional de desânimo para os investimentos produtivos.

Como resultado dessa forte redução da taxa global dos investimentos, a economia perdia fôlego e os ganhos de produtividade tendiam a zero. O mercado de trabalho, porém, ainda mostrava algum dinamismo, pois alguns mecanismos que haviam sido implementados ainda no período Lula, como o aumento real do salário mínimo ${ }^{12}$ e a expansão do crédito, ${ }^{13}$ continuaram atuando, impulsionando a massa salarial e o consumo das famílias (embora a taxas declinantes em comparação com o período 2004-2010). Ademais, o mercado de trabalho ainda aquecido propiciou condições de negociação de ganhos salariais reais, apesar das evidências de desaceleração da atividade econômica - especialmente na indústria.

Nesse contexto de perda de dinamismo dos investimentos e de pressões inflacionárias que só não se materializavam de forma mais efetiva por conta de uma estratégia de represamento de preços administrados, o fôlego do crescimento econômico e do dinamismo do mercado de trabalho arrefecia e isso se refletia nos dados expostos tanto no Gráfico l (que se refere apenas ao emprego formal) como na Tabela 1 (que inclui o conjunto da ocupação), permitindo ainda uma redução (porém, a um ritmo cada vez menor) da taxa de desemprego (Gráfico 2). Desde o início do primeiro mandato de Dilma a perda de dinamismo do mercado de trabalho era evidente. 
Gráfico 1 - Geração líquida de postos formais de trabalho

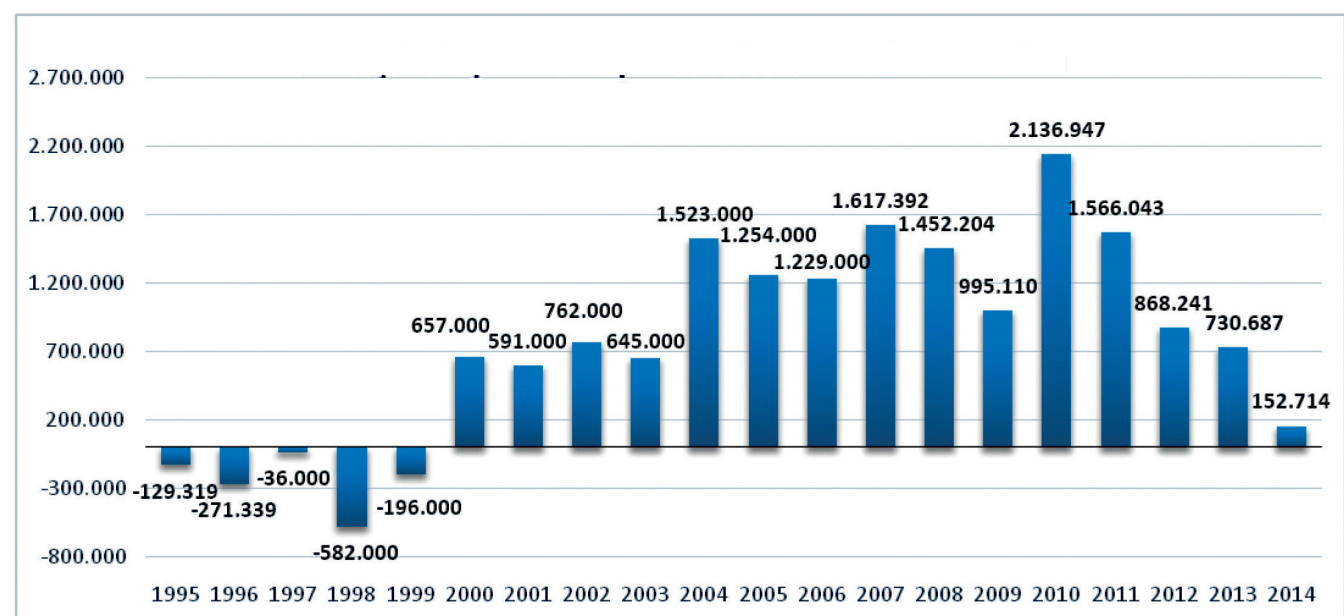

Fonte: Laged. Elaboraçāo propria.

O Gráfico 2 mostra a evolução da taxa de desemprego (média anual), segundo informações divulgadas pela PME (tendo como referência, portanto, as seis principais regiões metropolitanas do Brasil ${ }^{14}$ ). A trajetória da taxa de desemprego é claramente descendente na maior parte do período, notadamente a partir de 2004. O baixo patamar atingido pela taxa de desemprego em 2013/2014 acendeu um debate acerca da hipotética situação de pleno emprego que estaria vigorando na economia brasileira, ao mesmo tempo que também ensejou uma discussão a respeito das causas desse comportamento do desemprego. Mattos e Lima (2015) enfrentam essas duas questões. Após argumentarem, com base em resultados de um estudo econométrico, que a redução da taxa de desemprego esteve fortemente correlacionada (e determinada) pelo crescimento econômico ocorrido no período 2002-2013, os autores ponderam, com base em outros indicadores (entre os quais alguns que revelavam a existência ainda de elevada informalidade no mercado de trabalho) e tendo como referência algumas reflexões teóricas, que a economia brasileira não operava em pleno emprego em meados de 2013, apesar de ter, naquele momento, atingido o patamar mais baixo de uma longa série histórica.

O papel do crescimento do PIB foi decisivo para a redução da taxa de desemprego ocorrida no período (Mattos; Lima, 2015), mas para tal resultado também colaborou a desaceleração do crescimento demográfico ocorrida desde o início da década, além de certa redução da taxa de participação (PEA/PIA). ${ }^{15}$

A Tabela 1 revela a evolução de indicadores do mercado de trabalho brasileiro nos anos 2000, até 2013, segundo as PNAD, o que permite captar a evolução da informalidade. Os dados mostram criação de cerca de 17 milhões de ocupações entre 2002 e 2013 , o que significa pouco mais do que 1,5 milhão de ocupações por ano, em média, para o conjunto do país. Nesse mesmo período, a PEA cresceu em 15,6 milhões de pessoas. Esse crescimento da ocupação acima do crescimento da PEA explica a redução significativa do número e da taxa de desemprego. 
Gráfico 2 - Taxa média anual de desemprego

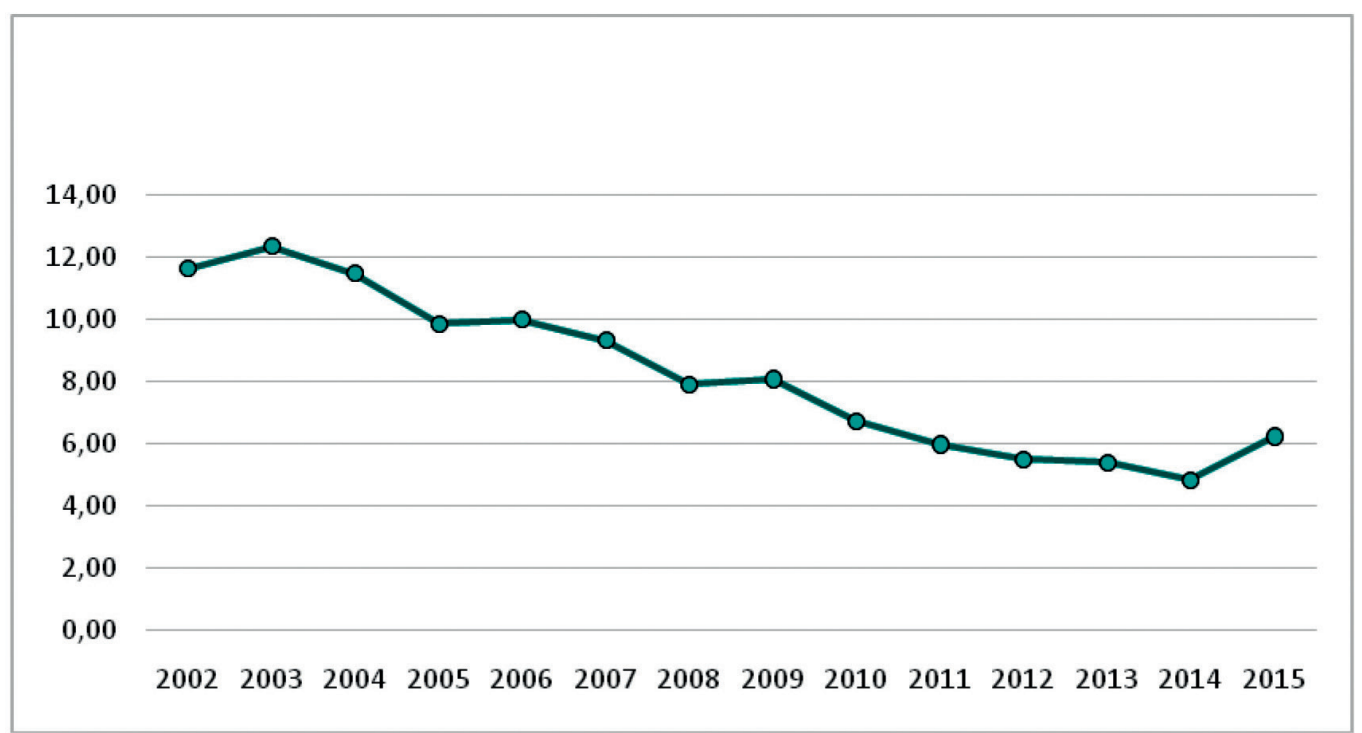

Fonte: PME/IBGE. Elaboração própria.

Mais do que apenas tratar da expansão da ocupação, deve-se salientar que houve um processo de significativo aumento da formalização das relações de trabalho, ${ }^{16}$ medida como o somatório entre emprego assalariado com carteira assinada, funcionários estatutários do setor público e empregadores. $\mathrm{O}$ indicador de formalização do mercado de trabalho assim medido saltou de 39,9\% do conjunto dos ocupados, em 2002, para 51,0\% em 2013. O crescimento da economia, potencializado pela expansão das políticas públicas já mencionadas, aqueceu o mercado interno e melhorou as condições de barganha dos trabalhadores, abrindo espaço para aumentos reais de salários (e da massa salarial), por sua vez favorecidos pela própria trajetória duradoura de um desemprego declinante, dessa forma tornando possível reverter o processo de informalização das relações de trabalho que vinha ocorrendo desde o início dos anos 1980.

Além da formalização do mercado de trabalho, outro processo de mudanças que marca uma reversão histórica, em comparação com a realidade que vinha caracterizando o mercado de trabalho dos 25 anos que precederam o crescimento que se inicia em 2004 foi a redução da desigualdade da renda do trabalho, expressa no Gráfico 3 pela evolução do Índice de Gini ${ }^{17}$ da distribuição da renda entre os indivíduos. Tal fenômeno ocorreu concomitantemente a um aumento real médio anual dos rendimentos do trabalho de cerca de 4,5\% entre 2004 e 2013 (segundo dados da PNAD).

O Gráfico 3 revela a redução contínua da desigualdade da distribuição dos rendimentos, referentes à renda média domiciliar per capita entre os indivíduos. Os dados mostram um arrefecimento da queda da desigualdade a partir de 2011 , não por acaso o ano a partir do qual a economia passou a se desacelerar. 
Tabela 1 - Indicadores selecionados do mercado de trabalho, Brasil (2002-2013)

\begin{tabular}{|c|c|c|c|c|c|c|c|c|c|}
\hline \multicolumn{9}{|c|}{ Números absolutos, em milhões, ou dados em percentual quando especificado. } & difer. $\left({ }^{*}\right)$ \\
\hline Indicadores/Ano & 2002 & 2004 & 2005 & 2007 & 2008 & 2009 & 2012 & 2013 & $13-02$ \\
\hline $\mathrm{PIA}^{1}$ & 143,122 & 150,846 & 153,722 & 157,777 & 160,514 & 164,640 & 171,032 & 173,132 & 30,010 \\
\hline $\mathrm{PEA}^{2}$ & 87,750 & 93,563 & 96,682 & 97,875 & 99,478 & 102,281 & 102,460 & 103,401 & 15,651 \\
\hline Ocupados $^{3}$ & 79,709 & 85,246 & 87,695 & 89,928 & 92,402 & 93,784 & 96,098 & 96,659 & 16,950 \\
\hline Desocupados & 8,041 & 8,317 & 8,987 & 7,947 & 7,076 & 8,497 & 6,363 & 6,742 & $-1,299$ \\
\hline Taxa de desemprego (em \%) & 9,16 & 8,89 & 9,30 & 8,12 & 7,11 & 8,31 & 6,21 & 6,52 & $-2,64$ \\
\hline Total de Empregados & 43,233 & 46,969 & 48,209 & 51,431 & 54,103 & 54,914 & 59,401 & 59,901 & 16,668 \\
\hline $\begin{array}{l}\text { Empregados com registro } \\
\text { em carteira }\end{array}$ & 23,367 & 25,800 & 27,126 & 29,735 & 31,834 & 32,743 & 37,780 & 38,513 & 15,146 \\
\hline $\begin{array}{l}\text { Militares e funcionários } \\
\text { públicos estatutários }\left({ }^{* *}\right)\end{array}$ & 5,092 & 5,605 & 5,516 & 6,131 & 6,409 & 6,697 & 7,070 & 7,138 & 2,046 \\
\hline $\begin{array}{l}\text { Empregados sem registro } \\
\text { em carteira }\end{array}$ & 14,775 & 15,563 & 15,567 & 15,565 & 15,860 & 15,475 & 14,552 & 14,250 & $-0,525$ \\
\hline Trabalhadores domésticos & 6,174 & 6,515 & 6,694 & 6,652 & 6,612 & 7,295 & 6,511 & 6,474 & 0,300 \\
\hline Trabalhadores por conta-própria & 17,747 & 18,740 & 18,980 & 19,064 & 18,719 & 19,209 & 19,832 & 19,924 & 2,177 \\
\hline $\begin{array}{l}\text { Trabalhadores para o próprio } \\
\text { consumo }\end{array}$ & 3,306 & 3,536 & 4,078 & 4,058 & 4,176 & 3,936 & 3,822 & 4,342 & 1,036 \\
\hline Empregadores & 3,380 & 3,500 & 3,705 & 3,368 & 4,145 & 4,035 & 3,620 & 3,623 & 0,243 \\
\hline Não-remunerados & 5,868 & 5,986 & 6,030 & 5,355 & 4,648 & 4,395 & 2,912 & 2,395 & $-3,473$ \\
\hline $\begin{array}{l}\text { PARTICIPAÇÃO DA OCUPAÇÃO } \\
\text { FORMAL }(\mathrm{em} \%)\left({ }^{* * *}\right)\end{array}$ & 39,9 & 40,9 & 41,4 & 43,6 & 45,9 & 46,4 & 50,4 & 51,0 & 11,03 \\
\hline $\begin{array}{l}\text { PARTICIPAÇÃO DA OCUPAÇÃO } \\
\text { PRECÁRIA }(e m \%)\left(^{* * * *}\right)\end{array}$ & 60,1 & 59,1 & 58,6 & 56,4 & 54,1 & 53,6 & 49,6 & 49,0 & $-11,03$ \\
\hline
\end{tabular}

Fonte: PNADs/IBGE. Elaboração própria.

Nota: 1) População com 10 ou mais anos de idade;

2) Trabalhadores ocupados com 10 anos ou mais de idade no trabalho principal da semana de referência;

(*) diferença, em números absolutos, entre 2013 e 2002. Nos casos da taxa de desemprego e dos índices de formalização, dados em pontos percentuais. $(* *)$ não inclui celetistas que trabalham no setor público. $(* * *)$ inclui com carteira, militares e funcionários públicos estatutários e empregadores. $(* * * *)$ inclui todas as demais formas de ocupação, não mencionadas acima.

Gráfico 3 - Evolução do índice de Gini

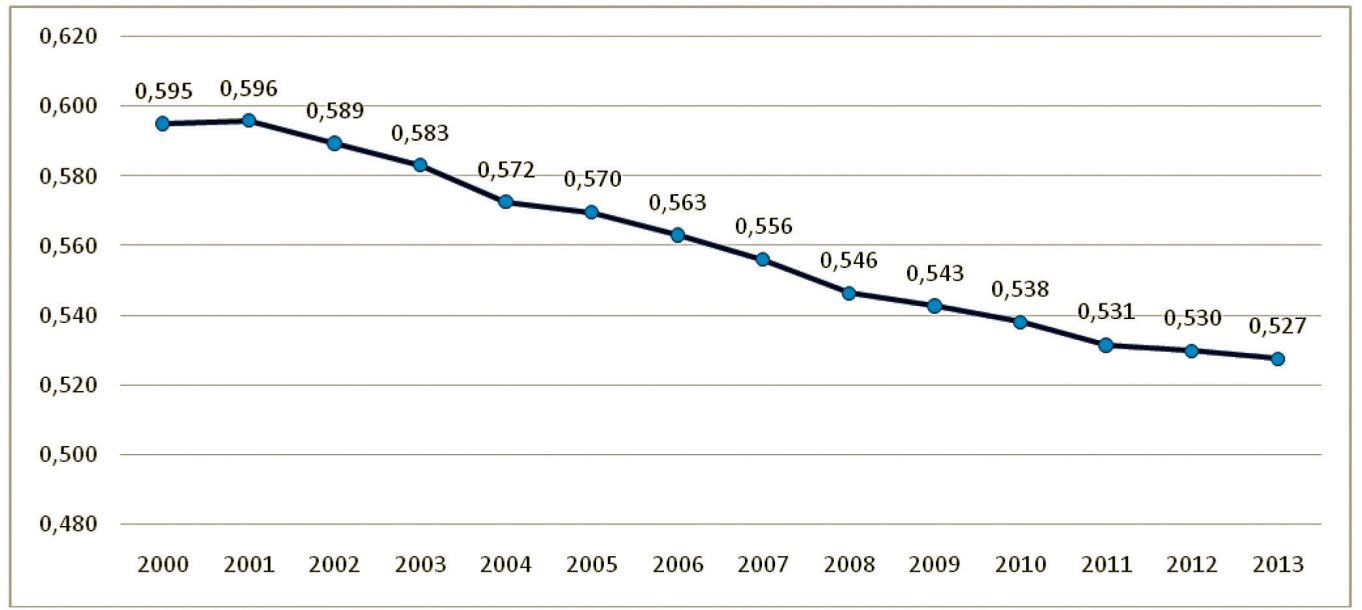

Fonte: Ipeadata. Elaboração própria. 
Essa redução das desigualdades de rendimentos deflagrou um amplo debate sobre as suas causas, sendo consensual que tanto o mercado de trabalho quanto as políticas sociais tiveram papel importante. Trabalho organizado por Calixtre (2014) sintetiza as contribuições teóricas e empíricas a respeito do tema. Tomando um período relativamente mais longo do que o mencionado acima, situação que permite conclusões estatisticamente mais robustas, Calixtre (2014) avalia que o mercado de trabalho contribuiu com $71 \%$ do crescimento da renda entre 1992 e 2012 e foi responsável por $47 \%$ da redução da desigualdade; complementarmente, mostra que a seguridade social contribuiu com $23 \%$ do crescimento da renda no mesmo período e com $15 \%$ da redução da desigualdade, enquanto $24 \%$ da redução da desigualdade se deveram ao papel exercido pelos programas de transferência de renda (constitucionais e também pelo Bolsa Família).

Deve-se ponderar, contudo, que, além da demonstrada desaceleração na criação de postos de trabalho, ocorrida a partir de meados de 2013, a qualidade desses deveria ser analisada com mais cuidado, pelo menos para alertar sobre as dificuldades que se projetam para o futuro.

O Gráfico 4 revela a evolução do perfil do emprego formal segundo faixas de remuneração, segundo a Rais. ${ }^{18}$ Os dados mostram que, entre 2002 e $2013,{ }^{19}$ aumentou expressivamente o número de empregos com remuneração abaixo de dois salários mínimos, seguida por um modesto (mas nítido) crescimento dos empregos com remuneração entre dois e cinco salários mínimos, e uma relativa estagnação do número de ocupações com rendimentos de cinco salários mínimos ou mais, em valores de cada ano. Os dados que deram origem a esse Gráfico 4 mostram que entre 2002 e 2013 foram criados cerca de 14 milhões de empregos formais e que cerca de $97 \%$ deles tinham remuneração até cinco salários mínimos, e mais de três quartos até dois salários mínimos. Dessa forma, em 2013 , cerca de $55 \%$ das ocupações formais tinham rendimentos equivalente a até dois salários mínimos daquele ano, e cerca de $86 \%$ até cinco salários mínimos. Em 2002, essas proporções eram iguais a, respectivamente, 39\% e 78\%, levando em conta o salário mínimo daquele ano. Mesmo considerando-se que o valor real do salário mínimo, no referido período, aumentou expressivamente, não sendo possível comparar rendimentos reais por ocupação tomando-os por intervalos de múltiplos do salário mínimo de cada ano, os resultados do gráfico revelam um perfil de rendimentos do mercado formal de trabalho característico de uma economia de baixos salários, que parece se acentuar ao longo da década. Esse cenário é preocupante e certamente se relaciona à já mencionada perda de dinamismo da produção industrial, setor que abriga em suas atividades uma proporção de altos salários maior do que em outros setores de atividade. 
Gráfico 4 - Evolução do número de empregos formais, por faixa de remuneração, entre 2002 e 2013

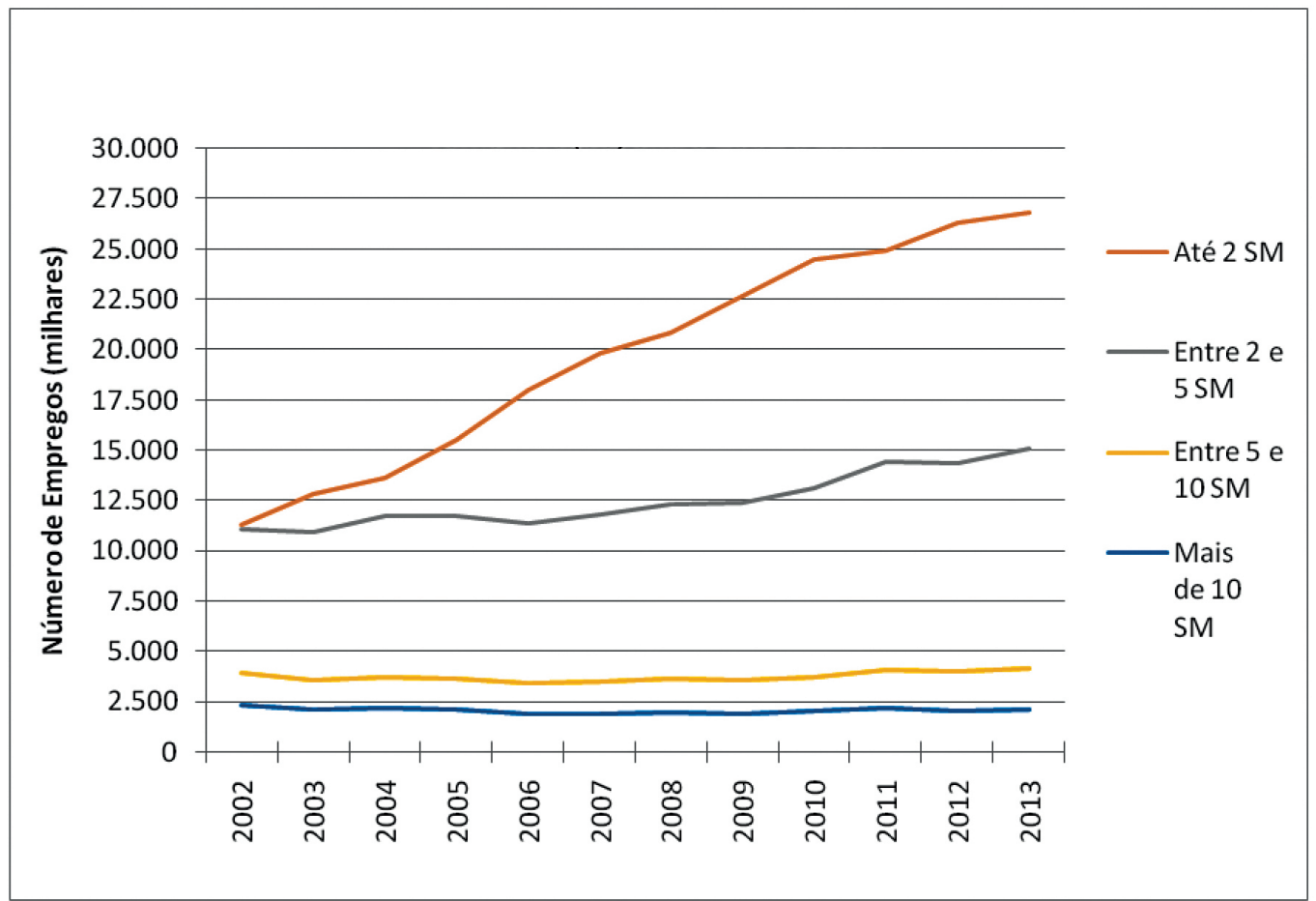

Fonte: Rais/MTE. Elaboração própria.

Do ponto de vista setorial, compilação de microdados das PNAD feita para redigir este artigo revela que, entre 2002 e 2013, a participação das ocupações vinculadas à indústria de transformação caiu de $15,4 \%$ para $13,7 \%$ da PEA não agrícola, tendo sido mais intensa a queda ocorrida justamente a partir de 2009, quando o cenário internacional acentuou as dificuldades de competitividade externa da indústria brasileira, diante das decisões estratégicas tomadas pela "fábrica asiática" (Bastos, 2015) e seus efeitos na divisão internacional do trabalho (Belluzzo, 2015). A contrapartida desse declínio se concentrou na expansão da participação das ocupações do terciário, mais especificamente aquelas relacionadas a alojamento/alimentação e aos serviços de educação, saúde e sociais, além de transportes/armazenagem e comunicação. Considerando-se apenas dados de emprego formal, o cenário setorial é semelhante: os dados mais atualizados disponíveis, divulgados pelo Caged, que revelam que, neste ano 2015, até julho (inclusive; série sem ajuste), foram fechados, em termos líquidos, 547.438 postos formais de trabalho, dos quais 228.644 somente na Indústria de Transformação, ou seja, cerca de $42 \%$ do total; tais números sugerem concentração da crise nas atividades industriais, dado que - só para registro - estas atividades, em dezembro de 2013, segundo dados oficiais da Rais, representavam 16,9\% do total de empregos formais do país (contra cerca de 17,2\% em 2012 e 18,8\% em 2006). Trata-se de uma trajetória preocupante do emprego na atividade 
industrial, a qual também tem revelado perda de participação no PIB nos anos recentes, atingindo, em 2014, um patamar de cerca de apenas 13\% do PIB, semelhante ao que vigorava na economia do país antes da implementação do Plano de Metas de JK!!

\section{Conclusões}

A melhoria do cenário externo no início do governo Lula, com ascensão dos preços das commodities e expansão da demanda chinesa, ampliou o raio de manobra para que os governos petistas pudessem implementar seu compromisso histórico com a adoção de políticas sociais, inicialmente de maneira tímida, mas a seguir de forma mais expansiva, dado que o aquecimento inicial da atividade econômica permitiu ampliação de gastos públicos mesmo sem que tenha sido abandonado o autoatribuído objetivo de manter expressivos superávits primários. A ampliação dos gastos públicos correntes e em infraestrutura, o maior protagonismo dos bancos públicos na expansão do crédito, bem como os efeitos dos aumentos substantivos do salário mínimo real explicam o fato de que os doze anos iniciais de governos petistas produziram resultados muito melhores, em termos de geração de postos de trabalho (e redução do desemprego), de combate à pobreza e de redução da desigualdade de renda do trabalho, do que aqueles que caracterizaram os anos 1990 no Brasil.

Este estudo apontou, porém, que o forte dinamismo na geração de postos de trabalho concentrou-se em empregos de baixos rendimentos, o que parece refletir, de modo geral, dificuldade da atividade econômica para gerar ganhos sustentáveis de produtividade e, em especial, para promover expansão sustentada das atividades industriais. Um dos principais desafios que se colocam para os formuladores de política econômica brasileira e, por conseguinte, para o nosso mercado de trabalho, é justamente recuperar a capacidade de crescimento da indústria, setor de atividade responsável pelo espalhamento de ganhos de produtividade para toda a atividade econômica, ${ }^{20}$ e que reúne postos de trabalho com salários acima da média dos demais setores.

O enfrentamento desse desafio, porém, não é trivial, diante do cenário atual do capitalismo internacional, notadamente (mas não apenas) devido ao efeito que este gera em termos de (re)divisão internacional do trabalho; e diante do cenário interno, devido tanto a fatores políticos quanto a problemas econômicos estruturais.

A consolidação de um arco de alianças de classe para conduzir essas transformações não é fácil, por uma série de fatores. Em primeiro lugar, porque, conforme alerta Bastos (2015, p.65), nossa burguesia industrial tornou-se compradora e rentista, adaptando-se aos desdobramentos da política macroeconômica adotada desde os anos 1990, que produziu, entre outros resultados, um processo de descontinuidade das cadeias produtivas e redução da participação da produção industrial no PIB e do emprego industrial no conjunto da ocupação, conforme procuramos argumentar neste ensaio. A "financeirização da riqueza”, 
que caracterizou o capitalismo desde o início do último quarto do século XX, conforme apontaram os trabalhos seminais de François Chesnais, ${ }^{21}$ parece ter produzido aqui desdobramentos ainda mais devastadores sobre as decisões de produção industrial, dadas as historicamente e muito altas taxas de juros reais que vigoram (ainda hoje) na economia brasileira. Dessa maneira, a possibilidade de se estabelecer uma aliança de classes algo semelhante ao que ocorreu no Brasil nos tempos do nacional-desenvolvimentismo, reunindo setores organizados do mundo do trabalho e parte da burguesia industrial, parece tornar-se cada vez mais improvável, dado que juros altos e câmbio valorizado, embora não sejam, em princípio, elementos que favoreçam a criação de empregos industriais, revelam-se funcionais para a rentabilidade do capital, inclusive de empresas cujo lócus original de acumulação seja o setor produtivo. A ampliação de "lucros de tesouraria", da mesma forma como já vinha alertando Chesnais com relação à experiência do capitalismo em países desenvolvidos, parece ter sido incorporada à prática e às estratégias dos grandes grupos empresariais sediados no Brasil.

Além disso, a consolidação de um padrão de acumulação que recupere o papel central da indústria só terá guarida se as lideranças políticas e as autoridades econômicas encarregadas dessa tarefa quiserem (e conseguirem) enfrentar o pensamento econômico hegemônico, cada vez mais estabelecido pela vulgata liberal/financista, que encontra eco, cada vez maior, há alguns anos, na chamada mídia “especializada” em temas econômico-financeiros. Essa mesma imprensa, por ser desregulamentada e historicamente pouco comprometida com a democratização da informação (Mattos; Simões, 2005), mostra-se pouco comprometida com o verdadeiro desenvolvimento da Nação, ${ }^{22}$ interditando o debate econômico.

Também se deve ter claro, de forma mais imediata, que as recentes medidas tomadas no início do segundo mandato de Dilma Rousseff vêm promovendo uma reversão muito rápida de indicadores de mercado de trabalho, conforme este artigo procurou descrever em breves palavras.

O "austericídio" (medidas de austeridade fiscal que, na verdade, têm provocado maior recessão e queda da arrecadação, mostrando-se autodestrutivas) do segundo mandato tende a piorar ainda mais o quadro descrito pelos dados mais recentes divulgados pela PNAD contínua ou por outras pesquisas. Em um país como o Brasil, os momentos de verdadeiro desenvolvimento econômico sempre foram aqueles que se apoiaram na expansão do mercado interno, e assim terá que ser em breve futuro, ainda mais no momento atual da economia internacional, em que a expansão das exportações encontraria muitas dificuldades, diante da recessão mundial. O que este artigo procurou mostrar é que, apesar de termos contado com um cenário internacional favorável no período 2004-2008 (principalmente), os melhores resultados em termos de expansão da renda e de redução (embora tímida; e - agora sabemos - frágil) da desigualdade (em momento em que a mesma aumentava em quase todos os países do mun- 
do, conforme mostraram dados reunidos em Oxfam, 2014) foram viabilizados pelas políticas voltadas para o mercado interno, como a valorização importante e duradoura do salário mínimo, a expansão das transferências de renda, o aumento do crédito para as famílias e a formalização do emprego. Essa trajetória somente será mantida se e quando houver consenso ideológico contra as atuais medidas de "austericídio" e quando houver um efetivo e bem-sucedido esforço de reindustrialização, valorizando o mercado interno e apoiando a recuperação econômica nele, conforme ensinou, há décadas, mestre Furtado.

\section{Notas}

I O saldo comercial subiu de US\$24,9 bi, em 2003, para US\$33,8 bi em 2004, especialmente por causa de significativo aumento das exportações, que saltaram de US\$ 73,1 bilhões, em 2003, para US\$ 96,5 bilhões em 2004.

2 Para a expansão do crédito, teve papel importante, já no final de 2003, a criação do chamado "crédito consignado", que tinha como lastro o próprio salário dos trabalhadores. Essa medida foi fruto de um acordo entre os sindicatos e os bancos, para o qual teve destaque a atuação da CUT. Nos anos seguintes, essa mesma modalidade de empréstimos pessoais foi estendida aos servidores públicos e aos aposentados e pensionistas do INSS, o que colaborou decisivamente para a expansão do crédito às famílias. Em 2004 também foi promulgada a Lei de Falências, que facilitou a recuperação de empréstimos por parte de empresas em dificuldades financeiras. Deve-se registrar, ademais, que a ampliação do crédito teve um efeito adicional, embora indireto, na evolução do perfil do mercado de trabalho, pois o acesso a este somente é possível a empresas que estejam formalizadas (o que inclui o respeito à legislação trabalhista, ou pelo menos para uma parcela de seus empregados). Em contexto de crescimento econômico, as compras feitas pelo governo também tendem a se expandir e, dessa forma, isso estimulou a formalização de empresas, que, assim, poderiam também disputar essa fonte de demanda. A adoção do sistema de simplificação tributária, denominado SIMPLES, também estimulou a formalização de empresas, notadamente de pequenos negócios, os quais concentram a maior proporção de empregados sem carteira assinada. Para mais detalhes sobre essas questões e sobre o papel fiscalizatório dos vários organismos do Estado sobre a legalidade das relações de trabalho, ver Baltar (2015).

3 Doravante, até o final desta seção, todos os dados mencionados de geração de empregos formais estão referenciados e ilustrados no Gráfico 1 , a seguir.

4 Santos (2013) lembra que o salário mínimo ganhou impulso com a campanha realizada conjuntamente pelas centrais sindicais, e resultou numa elevação do seu poder de compra de mais de $50 \%$, entre 2003 e 2010 . Essa política foi fundamental para a expressiva elevação dos salários de base, das aposentadorias e pensões, dos Benefícios de Prestação Continuada (BPC) - destinados às pessoas pobres com mais de 70 anos e sem aposentadoria e de outros benefícios sociais e previdenciários (seguro-desemprego, seguro-acidentes, benefícios pagos aos afastados por doenças etc.).

5 Estudo elaborado por Baltar et al. (2010) menciona pesquisa do Dieese segundo a qual, em cada ano entre 2005 e 2009 , esteve próximo de (ou foi superior a) $90 \%$ o percentual de categorias que, em negociações coletivas, conseguiram obter reajustes salariais acima da inflação anual. 
6 Conforme mostrou Souza (1980).

7 Ao conceder desonerações tributárias, inicialmente e para o setor automobilístico e posteriormente para produtos da "linha branca", o governo abriu mão de arrecadação, mas fomentou a manutenção do consumo ou pelo menos parte dele, evitando maior aprofundamento (e duração) da recessão, naquele momento (tais políticas, de maneira semelhante formuladas alguns anos depois, já no primeiro mandato de Dilma Rousseff, não trariam os mesmos resultados).

8 O salário mínimo real cresceu 70\% entre 2004 e 2014, o que mostra o êxito de seu programa de valorização - programa esse que foi mantido intacto pelo primeiro mandato de Dilma (o aumento real, durante o seu primeiro mandato, somente não foi mais expressivo por que o PIB cresceu menos do que no período Lula, em média).

9 Conforme lembra Bastos (2015), os juros internos reais e o superávit primário, durante os anos Lula, estiveram acima dos da maioria dos países da América do Sul, os quais, não por acaso e talvez não apenas por esses motivos, tiveram crescimento maior do que o Brasil. Vale também registrar que os gastos com juros da Dívida Interna representaram cerca de $6,5 \%$ do $\mathrm{PIB}$, em média anual, nos oito anos de FHC, contra $6,3 \%$ nos anos de Lula (média anual).

10 Durante boa parte do primeiro mandato de Dilma Rousseff, o câmbio se apreciou, mas não havia tanto espaço como o que caracterizara o período Lula, sem contar que os efeitos danosos sobre a produção industrial são cumulativos e ainda mais nocivos quando enfrentam uma divisão internacional do trabalho cada vez mais adversa ao Brasil, conforme comentaremos logo a seguir.

11 Mattos e Carcanholo (2012) já alertavam, com base em dados então disponíveis apenas até 2010, para o fato de que a indústria brasileira não era afetada apenas no mercado interno por importações provenientes da China, mas também havia sinais claros de perda de espaço em terceiros mercados (nomeadamente em países da América do Sul) para os quais nossas exportações industriais antes se dirigiam e que passaram a ser deslocadas por exportações manufatureiras chinesas. Bastos (2015) também analisa a reordenação da divisão internacional do trabalho pós-crise de 2008 e aponta para as crescentes dificuldades encontradas pela indústria brasileira, em especial destacando a quebra ou descontinuidade de cadeias produtivas importantes da atividade manufatureira instalada no Brasil.

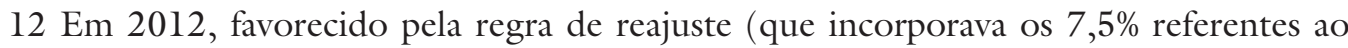
aumento do PIB de dois anos anteriores), o salário mínimo teve um significativo reajuste nominal, que, em termos reais, representou, no ano, ganho de 8,4\%. Em 2013, o ganho real seria de apenas $2,4 \%$.

13 A expansão do crédito em relação ao PIB continuou a ocorrer entre 2011 e 2013, e ainda em meados de 2014, principalmente devido à expansão do crédito advindo do setor público.

14 E não o conjunto dos municípios brasileiros, como nos dados do Caged que ilustram o Gráfico 1.

15 A taxa de participação depende de diversos fatores, relacionados a aspectos demográficos, mas também a aspectos econômicos (como o estágio do ciclo econômico, a evolução do rendimento médio do trabalho, do rendimento médio familiar etc.) e a aspectos institucionais (situação e regras da Previdência Social, incluindo valores dos benefícios pagos; existência ou não, e abrangência de sistemas de seguro-desemprego; 
facilidades para as famílias deixarem seus filhos em creches ou escolas etc.). Todos esses elementos, bem como seus efeitos sobre a evolução da taxa de desemprego, foram analisados em Mattos e Lima (2015), não cabendo aqui, por falta de espaço, tecer considerações muito longas a seu respeito, mas apenas destacar que, tudo o mais mantido constante, a redução da taxa de participação gera redução da taxa de desemprego.

16 A formalização do mercado de trabalho significa que uma proporção maior dos ocupados encontra-se protegido pela legislação trabalhista, social e previdenciária brasileira.

17 O Índice de Gini é um índice bastante usado na medição de desigualdade, variando de zero (perfeita igualdade) a 1 (total desigualdade).

18 Dados referem-se aos respectivos estoques de emprego formal no dia 31 de dezembro de cada ano.

19 Os dados da Rais de 2014 ainda não foram disponibilizados pelo Ministério do Trabalho e Emprego.

20 Nos últimos anos, inúmeros estudos vêm se dedicando a discutir a problemática da desindustrialização, dos quais sugerimos a leitura de, pelo menos: Cano (2012), Dieese (2011) e Mattos e Fevereiro (2014), que advogam pela ideia de que está em curso um processo de desindustrialização, além de Squeff (2012), que, por outro lado, reúne argumentos críticos da hipótese de desindustrialização no Brasil.

21 Ver, pelo menos, Chesnais (1996a; 1996b; 1997); Serfati (1996) e Bastos (2015).

22 Um exemplo dessa discussão encontra-se em Brittos e Bolaño (2005), cujos artigos abordam e problematizam, para o caso brasileiro, um cenário parecido ao descrito por McChesney (2000), nos marcos da chamada Economia Política da Comunicação.

\section{Referências}

BALTAR, P. E. A. Crescimento da economia e mercado de trabalho no Brasil. Texto para Discussão IPEA 2036. Brasília: IPEA, fev. 2015.

BALTAR, P. E. A. et al. Trabalho no governo Lula: uma reflexão sobre a recente experiência brasileira. Global Labour University Working Papers. Paper n. 9, May 2010.

BARBOSA, N. Dez anos de politica econômica. In: SADER, E. Lula e Dilma: dez anos de governos pós-neoliberais no Brasil. São Paulo: Boitempo; Flacso, 2013.

BASTOS, P. P. Z. Austeridade para quem? A crise global do capitalismo neoliberal e as alternativas no Brasil. Texto para Discussão 257. Instituto de Economia/Unicamp. ago. 2015.

BElluzZO, L. G. M. A China, o Brasil e a indústria. Carta Capital, São Paulo, 6.5.2015.

BRITTOS, V.; BOLAÑO, C. (Org.) Rede Globo: 40 anos de poder e hegemonia. São Paulo: Paulus, 2005.

CAliXtre, A. B.; BIANCARELli, A. M.; CINTRA, M. A. M. (Ed.) Presente e futuro do desenvolvimento brasileiro. Brasília: Ipea, 2014.

CANO, W. A desindustrialização no Brasil. Texto para Discussão 200. Campinas: Instituto de Economia, Unicamp, 2012. 
CHESNAIS, F. A mundialização do capital. São Paulo: Xamã, 1996a.

Mondialisation financière et vulnérabilité systemique. In: La mondialisation financière: genèse, coût et enjeux. Paris: Syros, 1996b.

Mondializzazione del capitale e regime d'accumulazione a dominanza finanziaria. In: LUZI, J. (Org.) Miseria della mondializzazione. Roma: Strategia della Lumaca Edizioni, 1997.

DIEESE. Desindustrialização: conceito e a situação do Brasil. Nota Técnica. Número 100 , junho de 2011.

MATTOS, F. A. M.; CARCANHOLO, M. D. Amenazas y oportunidades del comercio brasileño con China. Lecciones para Brasil. Problemas del Desarrollo. Revista Latinoamericana de Economía, México, v.43, n.168, p.117-45 enero-marzo, 2012.

MATTOS, F. A. M.; FEVEREIRO, J. B. ¿¿Se desindustrializa Brasil? Problemas del Desarrollo, v.45, p.35-62, 2014.

MATTOS, F. A. M.; LIMA, S. S. Apontamentos para o debate sobre o pleno emprego no Brasil. Economia e Sociedade, 2015 (no prelo).

MATTOS, F. A. M.; SIMOES, C. F. Elementos histórico-regulatórios da Televisão Brasileira. In: BRITTOS, V. C.; BOLAÑO, C. R. S. (Org.) Rede Globo: 40 anos de poder e hegemonia. São Paulo: Paulus, 2005. v.1, p.35-55. (encontra-se no prelo a edição de 2015, em alusão aos 50 anos da Rede Globo).

OXFAM. Gobernar para las élites: secuestro democrático y desigualdad económica. Informe de OXFAM, n.178, enero, 2014.

McCHESNEY, R. W. Rich Media, Poor Democracy-communication politics in dubious times. New York: New Press, 2000.

POCHMANN, M. Desigualdade econômica no Brasil. São Paulo: Ideias \& Letras, 2015.

SADER, E. Lula e Dilma: dez anos de governos pós-neoliberais no Brasil. São Paulo: Boitempo; Flacso, 2013.

SANTOS, A. L. Recuperação econômica e trabalho no governo Lula. Carta Social e do Trabalho, Campinas, n.24, out./dez. 2013.

SERRANO, F.; SUMMA, R. Aggregate Demand and the Slowdown of Brazilian Economic Growth from 2011-2014. Washington DC: Center for Economic and Policy Research, August 2015.

SERFATI, C. Le rôle actif des groupes à dominante industrielle dans la financiarisation de l'économie. In: CHESNAIS, F. (Org.) La mondialisation financière: genèse, coût et enjeux. Paris: Syros, 1996.

SOUZA, P. R. A Determinação dos salários e do emprego nas economias atrasadas. 1980. Tese (Doutorado) - Instituto de Economia/Universidade Estadual de Campinas. Campinas, 1980.

SQUEFF, G. C. Desindustrialização: luzes e sombras no debate brasileiro. Texto para Discussão 1747. IPEA/Brasília (DF). Junho de 2012. 
RESUMO - O objetivo deste estudo é avaliar a trajetória dos principais indicadores de mercado de trabalho brasileiro desde o início do governo Lula. Os dados revelam aumento da participação do emprego formal, do salário real médio e redução da desigualdade no período 2003-2014, mas alguns problemas revelados durante os doze anos iniciais mostram-se preocupantes, podendo ser agravados no médio prazo. Os dados do início de 2015 mostram aumento do desemprego e queda da massa salarial, como reflexo da política econômica que vem sendo adotada no início do segundo mandato de Dilma Rousseff. Nas conclusões, advoga-se pela necessidade de criação de um consenso político em favor de uma política econômica que seja apoiada no fortalecimento do mercado interno e na retomada da atividade industrial. São feitas também críticas ao papel que tem sido desempenhado pela imprensa especializada no debate sobre alternativas de política econômica.

PALAVRAS-CHAVE: Mercado de trabalho brasileiro, Salário mínimo, Distribuição de renda no governo Lula, Desindustrialização, Políticas sociais.

ABSTRACT - This study aims to assess the main indicators of the Brazilian labor market since the first mandate of president Lula (2003-2006). The data reveal increases in formal employment and in average real wages, as well as a reduction in income inequality during the 2003-2014 period. However, certain problems identified during these twelve years are worrisome and may even worsen in the near future. Data available for the first seven months of 2015 show rising unemployment and falling wages, a reflection of the economic policy that was adopted in the beginning of Dilma Rousseff's second term. In the conclusion, the article advocates the need to achieve political consensus around an economic policy based on strengthening the domestic market and on the recovery of industrial activity. Moreover, it criticizes the role of the specialized press in the debate on alternative economic policies.

KEYWORDS: Brazilian labor market, Minimum wage, Income distribution in the Lula administration, Deindustrialization, Social policies.

Fernando Augusto Mansor de Mattos é professor-pesquisador do Programa de PósGraduação em Economia (PPGE) da Faculdade de Economia da Universidade Federal Fluminense (UFF). Mestre e doutor em Economia pelo Instituto de Economia da Unicamp. Assessor da Presidência do Ipea entre 2008 e 2011. Membro do Grupo de Pesquisa intitulado Núcleo de Estudos em Economia Brasileira (NEB).

@ - fermattl@hotmail.com

${ }^{\text {I }}$ Faculdade de Economia, Universidade Federal Fluminese, Niteroi/Rio de Janeiro, Brasil.

Recebido em 3.9.2015 e aceito em 18.9.2015. 
